\title{
Aplicações de princípios da Informática na Educação para a Virtualização do Portfólio de Atividades Didáticas "A fada que tinha ideias"
}

\author{
Felipe Gabriel M. Serafim ${ }^{1}$, Humberto Rabelo ${ }^{1,2}$, Angela Maria C. Naschold ${ }^{1}$, \\ Danieli Silva de S. Rabelo ${ }^{1,2}$, Soraya Medeiros ${ }^{1,3}$, Daniel Icaro F. Diniz ${ }^{1}$, Jânio \\ Fernandes ${ }^{1}$ \\ ${ }^{1}$ Universidade Federal do Rio Grande do Norte (UFRN) - RN - Brasil \\ ${ }^{2}$ Universidade de Coimbra (UC) - Coimbra - Portugal \\ ${ }^{3}$ Programa de Pós-Graduação em Inovação em Tecnologias Educacionais (PPgITE) \\ felipe.gabriel.mariz@hotmail.com, \{hrabeloufrn, anaschold, rabrlodanni, \\ soraya.roberta.js, danielicaro10, juniorjanio2016\}@gmail.com
}

\begin{abstract}
This article describes the virtualization process of the Didactic History Portfolio "A fada que tinha ideias". This aims to make possible the application of literacy activities taking into account the reality of remote learning, such as reducing the cost of teaching materials that occurs in the physical application of this portfolio. The central methodological pillar for the development was the Cognitive Load Theory. The frameworks used were Construct 2 and Inkscape. After applying the evaluative questionnaires to pedagogue teachers, positive results were obtained regarding the usability of the portfolio.
\end{abstract}

Resumo. O presente artigo descreve o processo de virtualização do Portfólio Didático da História "A fada que tinha ideias". Este tem como objetivo tornar possível a aplicação de atividades de alfabetização levando em consideração a realidade do ensino remoto, tal como reduzir o custo com os materiais didáticos que ocorre na aplicação física deste portfólio. O pilar metodológico central para o desenvolvimento foi a Teoria da Carga Cognitiva. Os frameworks utilizados foram o Construct 2 e o Inkscape. Após aplicação dos questionários avaliativos aos professores pedagogos, obteve-se resultados positivos quanto a usabilidade do portfólio.

\section{Introdução}

A importância que a tecnologia vem ganhando no âmbito educacional é algo inquestionável, sobremaneira quando se trata da agilidade em compartilhar, publicar e pesquisar conteúdos didáticos. Porém, no início do ano de 2020 esta relação entre tecnologia e educação foi posta à prova, de uma maneira muito severa e repentina com a chegada do novo coronavírus, chamado de COVID-19. 
Com o fechamento das escolas e demais centros educacionais no Brasil e em boa parte do mundo por tempo indeterminado, a tecnologia que antes era apenas coadjuvante nas várias metodologias de ensino, passou a ter o papel principal, sendo a única forma de viabilizar a continuação das atividades educacionais, porém de forma remota. Como ressalta Cordeiro (2020) essas atividades online direcionadas aos alunos, apesar de todos os seus desafios e entraves, são cruciais para minimizar os prejuízos do período na ausência das aulas presenciais.

Em meio às dificuldades e limitações do ensino remoto, algumas ferramentas de ensino importantes, principalmente na etapa de alfabetização, não podiam ser utilizadas de maneira adequada em trabalho desenvolvido junto à comunidade educativa do estado do Rio Grande do Norte pelo Projeto Leitura + Neurociências: Interfaces na Educação Integral (Naschold et al, 2018) ${ }^{1}$. Este trabalho tem como objeto de relato a virtualização de material desenvolvido pelo referido projeto denominado de Portfólio Didático da História "A fada que tinha ideias" (Naschold, 2019), sendo o mesmo um material que porta atividades de leitura e escrita construídas a partir do livro de história infantil intitulado A fada que tinha ideias (Almeida, 1976).

O portfólio conta com diversas atividades de recorte e colagem, de escrita de textos e de mapas conceituais, dentre outras centradas nas teorizações da (1) Psicolinguística (Goodman, 1991; Leffa, 1996; Kato, 2007; Gombert, 1992; Halliday \& Hasan, 1976; Charolles, 1978; Solé, 2015; Pereira, 2009) e (2) das neurociências cognitivas da leitura (Dehaene, 2012), que, associadas à (3) Educação (Chevallard, 2013; Brousseau, 1996; Freire, 1988; Nicolescu, 1999; Novak, 2010), se conjugam de maneira interdisciplinar nas atividades propostas no portfólio.

Vale ressaltar que o Portfólio Didático da História "A fada que tinha ideias" (Naschold, 2019), mesmo antes do ensino remoto, em sua apresentação impressa, demandava alto custo de materiais, visto que sua aplicação para um único aluno necessitava da utilização de aproximadamente 40 folhas impressas. Une-se a isso o fato de que a presença do professor é de suma importância para esta aplicação, devido às constantes instruções, correções e revisões que devem ser realizadas no decorrer do processo, fazendo com que a utilização do portfólio fosse praticamente inviável na realidade do ensino remoto.

Considerando o cenário descrito, este artigo trata sobre o desenvolvimento de uma versão digital do Portfólio Didático da História “A fada que tinha ideias”, tendo como objetivo simular digitalmente, da forma mais coerente possível, as atividades antes realizadas de forma física. A versão digital desse portfólio também permite a medição de alguns dados em sua aplicação, como o tempo que o aluno gasta para realizar cada atividade e sua respectiva pontuação, desde que seja uma atividade em que a avaliação dentro do próprio software seja possível.

\footnotetext{
${ }^{1}$ Disponível em: <http://www.leituramaisneurociencias.com/> Acesso em: 15 set, 2021
} 
Neste contexto, o portfólio digital dimensionado pelo presente trabalho passa a integrar as atividades propostas à realidade educativa pelo projeto de pesquisa Leitura + Neurociências: Interfaces na Educação Integral, sendo o mesmo desenvolvido na versão digital utilizando-se o Framework Construct 2. Suas artes e demais artefatos que compõem as telas foram criados por intermédio da ferramenta gratuita de vetorização Inkscape.

O restante do artigo está organizado em seis seções: na Seção 2, são apresentados alguns trabalhos relacionados; na Seção 3, apresenta-se a fundamentação teórica, abordando a teoria da carga cognitiva e conceitos de informática na educação; a Seção 4 mostra os aspectos do Portfólio Digital da História "A fada que tinha ideias", bem como as avaliações de validação; na Seção 5, os resultados são apresentados; a Seção 6 traz a conclusão e as considerações finais.

\section{Trabalhos relacionados}

Exitosamente, Ceccon \& Porto (2020) desenvolveram o jogo digital Brincando com os Sons, que é direcionado à crianças com necessidades educacionais especiais e que apresentam atraso no desenvolvimento da linguagem. Em sua primeira aplicação avaliativa o jogo foi oferecido a crianças com Síndrome de Down de uma escola de Curitiba/PR. Salienta-se que além do poder de aprendizado oferecido pelos jogos educativos, os autores afirmam que tais jogos oferecem às crianças, uma forma lúdica de aprender, e como são atividades interativas e simples tornam o aprendizado mais atrativo. Para a criação do jogo foi utilizado o framework Construct 2 e o método de pesquisa Design Science Research. Questionários foram aplicados algumas vezes no processo de desenvolvimento, com a finalidade de levantar requisitos e melhorar o jogo. Por fim, pela avaliação do profissional especializado em educação especial, a utilização do jogo foi válida para apoiar o desenvolvimento da fala, em crianças de 3 a 5 anos de idade.

Lemos (2016) realizou uma pesquisa qualitativa com o intuito de demonstrar a importância dos jogos digitais como atividades interativas e de aprendizagem no processo de alfabetização. Aplicando jogos educativos com uma turma de alunos foi verificado que houve uma grande aceitação por parte deles, que relataram ter aprendido e se divertido bastante. A autora explica também que crianças no processo de alfabetização focam sua atenção em imagens, cores e movimentos e isso aumenta a sua concentração na realização das tarefas. Ela conclui afirmando que o aperfeiçoamento do aprendizado existe, e progride na medida em que os jogos se tornam mais desafiadores.

Melo, Segato, \& Mombach (2019) desenvolveram o jogo Apolo, uma adaptação digital do conhecido jogo de tabuleiro "Perfil". A metodologia utilizada foi o Progressive Web Apps em conjunto com estudo de caso na área de Geografia, em alunos do Ensino Médio. Os autores citam como problemática principal, a falta de motivação dos alunos aos estudos, e uma das consequências dessa falta de motivação, ser a 
dificultação do processo de aprendizado em sala de aula. Os resultados obtidos por meio de um questionário de aceitação do jogo, aplicado aos alunos, foram positivos e por fim, os autores concluem que a ferramenta se mostra com potencial para fortalecer os recursos educacionais digitais para o ensino básico brasileiro.

Os artigos supracitados trazem aspectos positivos acerca da utilização de jogos educacionais no ensino. Neste contexto, o Portfólio Digital da História "A fada que tinha ideias" torna-se uma ferramenta de ensino ainda mais relevante, visto que aplica esses aspectos positivos em atividades didáticas eficazes para o ensino, que já são utilizadas em sala de aula de maneira física.

\section{Fundamentação teórica}

\subsection{Teoria da carga cognitiva}

Como explica Santos, \& Tarouco (2007) a Teoria da Carga Cognitiva defende que a elaboração de materiais didáticos, principalmente os que utilizam multimídia, deve seguir alguns princípios para, assim, diminuir a sobrecarga cognitiva do aluno e potencializar seu aprendizado. É importante que a quantidade de informações existentes em uma tela esteja de acordo com a capacidade de assimilação do ser humano, se essa capacidade for excedida a aprendizagem será menos efetiva.

Dentre os princípios da teoria da carga cognitiva, Portfólio Digital da História "A fada que tinha ideias" apresenta os seguintes: 1) Princípio de Representação Múltipla: os alunos aprendem melhor quando acontece a combinação de palavras e imagens, do que no momento em que se usam somente palavras. Os textos presentes na tela do portfólio digital são apresentados sempre com imagens ou outros elementos gráficos; 2) Princípio de Proximidade Espacial: esse princípio é relativo à proximidade de palavras e imagens, ou seja, quando palavras e imagens correspondentes estão próximas em vez de afastadas. O portfólio digital mantém sempre o mesmo padrão de disposição de elementos em todas as fases, até por um motivo de organização e memorização; 3) Princípio da Coerência: refere-se à não utilização de palavras, imagens, sons ou quaisquer outros elementos, não relevantes para o assunto. $\mathrm{A}$ apresentação do conteúdo deve ser o mais objetiva e simples possível, assim a memória de trabalho ficará mais livre, e será capaz de processar um número maior de conhecimentos. No portfólio digital, todos os elementos apresentados em cena são relevantes para a realização das tarefas.

\subsection{Informática na educação}

O conceito de informática na educação, parte da utilização de meios computacionais e tecnológicos para auxiliar, promover ou mesmo possibilitar, a realização de atividades didáticas nos mais diferentes níveis de ensino. Essa utilização vem refletindo em 
melhorias consideráveis, e tornando cada vez mais simplificado e prático o ambiente de ensino, seja presencial ou remoto.

Deve-se ressaltar que embora a utilização da informática seja importantíssima para os processos de ensino, essa tecnologia não pode ser o único instrumento no ambiente didático, como ressaltam Oliveira, \& Porrozzi (2009) que enfatizam que não podemos abrir mão da reflexão do componente humano, e ainda, a tecnologia educacional deverá atender a um projeto político-pedagógico adequando-se a este e nunca o determinando.

Vale destacar que na maioria das escolas e centros de ensino do Brasil, a informática é utilizada de maneira simplista, retendo-se na maioria das vezes ao simples uso das funções básicas dos computadores e a utilização de equipamentos facilitadores como o retroprojetor, por exemplo. Isso em parte se dá por fatores culturais, como explica Bulhões et al. (2020) que a implantação dos recursos computacionais à educação deve acontecer de forma cuidadosa, já que se trata de novas práticas e envolve quebras de paradigmas antigos.

Diante dos aspectos supracitados, pode-se classificar a gamificação como uma sub-ferramenta valiosa, capaz de aprofundar e extrair ainda mais aspectos positivos do uso de informática na educação. Como explicam Smiderle, Rigo, \& Jaques (2019) a gamificação da educação é uma estratégia para aumentar o envolvimento dos alunos, incorporando elementos de jogos em um ambiente de aprendizagem. $\mathrm{O}$ objetivo é gerar níveis de engajamento e dedicação iguais aos que os jogos normalmente oferecem.

\section{Portfólio Digital da História "A Fada que tinha ideias"}

O Portfólio Digital da História “A Fada que tinha ideias" é uma aplicação gamificada em duas dimensões (2D), que contém 14 atividades didáticas dos mais variados tipos, que serão descritas posteriormente neste trabalho. Essas atividades foram retiradas de um portfólio físico, de mesmo nome, que já está sendo aplicado há alguns anos para alunos do nível de alfabetização. Deve-se deixar claro que a finalidade deste portfólio digital não é criar um conteúdo didático novo, ou teorias novas para impulsionar a alfabetização, mas sim, de simular digitalmente da maneira mais fiel possível, as atividades já existentes no portfólio físico.

\subsection{Desenvolvimento}

A seguir estão listadas as etapas de desenvolvimento do portfólio digital, (Figura 1), e suas respectivas explicações. 


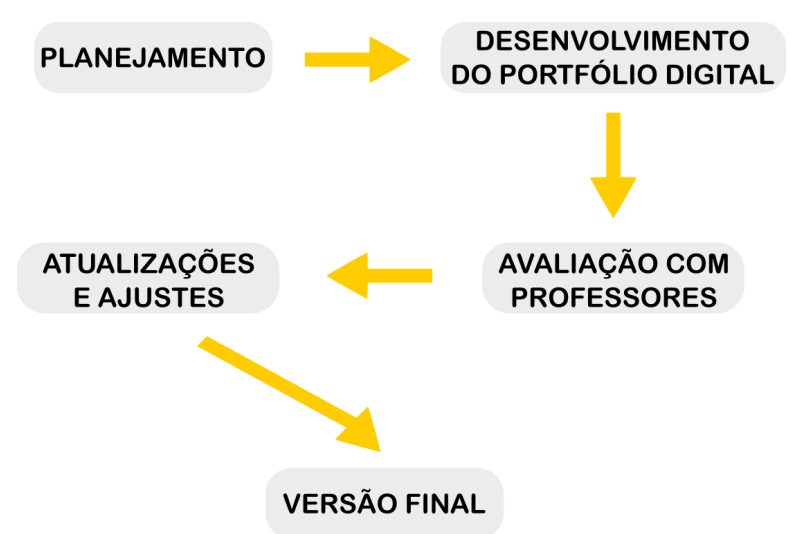

Figura 1. Processo de desenvolvimento. Fonte: 0 autor

\subsubsection{Planejamento}

$\mathrm{Na}$ etapa de planejamento foram realizadas reuniões com os professores responsáveis para discutir acerca dos prazos, dos métodos de desenvolvimento e das tecnologias utilizadas. Optou-se pela utilização do framework Construct $2^{2}$ como ferramenta de desenvolvimento, e do Inkscape ${ }^{3}$ como ferramenta artística. Tais ferramentas foram escolhidas devido serem fáceis de se utilizar, terem artefatos suficientes para a realização de todas as atividades definidas e por ambas terem versões gratuitas, o que reduziu o custo de desenvolvimento.

\subsubsection{Desenvolvimento e avaliações}

Como dito no início da seção, o portfólio digital é baseado em um portfólio físico, tornando a etapa de desenvolvimento mais rápida por não haver a necessidade de criar tudo do zero. A base - o portfólio físico - já estava pronta, e isso adiantou bastante o início da confecção dos elementos artísticos e da codificação em si.

O desenvolvimento das 14 tarefas, ou fases, se deu de maneira sistemática e sequencial. Como as tarefas não poderiam ser drasticamente modificadas, pois, poderiam acabar perdendo sua essência pedagógica, a cada desafio encontrado, eram realizados estudos para contorná-los e manter as tarefas o mais fiel possível às originais.

O portfólio digital não foi desenvolvido utilizando-se uma metodologia pré definida. Isso porque a volatilidade dos jogos educacionais impede que se adaptem perfeitamente a fôrmas já existentes, como evidenciam Oliveira, Fontoura \& Medina (2020). Como o jogo educacional parte de uma necessidade específica de ensino, cada desenvolvedor avalia as ferramentas mais adequadas para o desenvolvimento de seu produto, sem usar um processo padronizado completo como base. set, 2021.

${ }^{2}$ Disponível em: $<$ https://www.construct.net/en/make-games/games-editor $>$ Acesso em: 14

${ }^{3}$ Disponível em: <https://inkscape.org/pt-br/> Acesso em: 14 set, 2021. 
Após a fase de desenvolvimento ter acabado, foi realizada uma reunião online com diversos professores de escolas públicas dos anos iniciais do Ensino Fundamental; o portfólio digital foi-lhes apresentado, e eles opinaram, contribuindo para melhorias. Foi uma avaliação subjetiva e em conjunto, mas muito valiosa. Por tratar-se de uma reunião interdisciplinar, envolvendo conceitos de pedagogia e tecnologia, pôde-se retirar dela melhorias significativas para o portfólio digital.

\subsubsection{Ajustes e versão final}

Após a reunião de avaliação, melhorias foram feitas no portfólio digital. Foram adicionados: uma funcionalidade que mede o tempo e a pontuação dos alunos em cada fase; uma tela de pontuação no final das 14 fases; e um menu novo, que possibilita o acesso a qualquer fase de maneira direta, visto que antes as fases eram acessadas de forma sequencial.

Depois das correções, a versão final foi exportada para HTML 5, e o acesso foi disponibilizado para todos os professores e alunos que compõem o projeto de pesquisa, utilizando qualquer navegador de internet de maneira online.

\subsection{Mecânicas}

O portfólio digital conta com mecânicas variadas, de acordo com as atividades. Nesta subseção, são apresentados e explicados os tipos de atividades presentes e suas mecânicas, tais como a tela inicial e de pontuação. São elas:

Atividade de produzir texto (Figura 2): Este tipo de atividade é o mais comum no portfólio, aparecendo em 10 das 14 fases, ela conta também com uma mecânica única. Como não é possível que o portfólio digital em si, avalie os textos escritos de maneira completa, nas fases que existe algum tipo de produção textual, é realizado um print da tela, que pode ser baixado pelo aluno em forma de imagem e enviado ao professor responsável por alguma mídia de comunicação.

Atividade de arrastar e soltar (Figura 3): esta atividade equivale à atividade de recorte e colagem do portfólio físico. Ela aparece em 6 das 14 fases, contando com um sistema de verificação de acerto, quando o aluno arrasta a figura ou o texto correto para a lacuna correta. Nesse momento, acontece uma confirmação visual de que o aluno acertou, e o marcador de pontuação aumenta.

Atividades artísticas (Figura 4): estas atividades não envolvem nenhum tipo de avaliação e aparecem em 2 das 14 fases, de duas formas diferentes. A primeira forma consiste em uma tarefa de recriar a capa do livro $A$ fada que tinha ideias. Nesta tarefa, o aluno pode escolher uma dentre seis cores de fundo e arrastar algumas figuras pré definidas para compor a nova capa. Neste caso, um print também é realizado, para o aluno poder guardar ou enviar a nova capa que ele criou. A segunda forma diz respeito a uma atividade de desenho e pintura em que o aluno pode escolher uma cor e rabiscar livremente nos espaços predefinidos, mas de acordo com as instruções prévias. 
Atividade de Mapa Conceitual (Figura 5): esta atividade é encontrada em apenas 1 das 14 fases. Consiste na criação de um mapa conceitual com elementos de um capítulo específico do livro. Nesta atividade, também ocorre a função de print para compartilhamento do resultado, e o aluno é livre para arrastar as palavras e as setas que compõem o mapa conceitual da maneira que preferir.

Vale ressaltar que essas atividades listadas podem aparecer em mais de uma fase do portfólio digital simultaneamente, ou seja, as fases podem ser compostas por mais de uma atividade diferente.

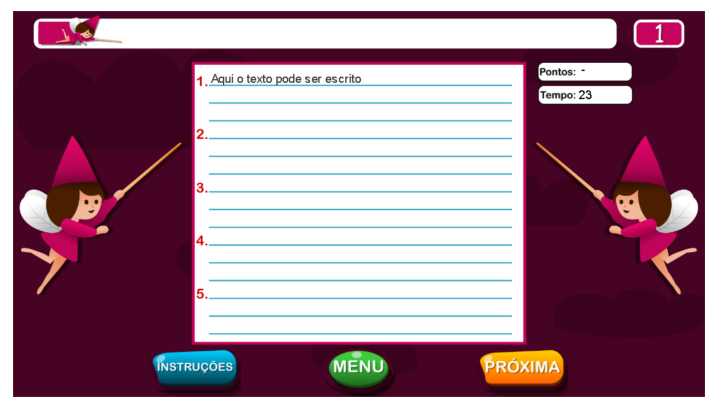

Figura 2. Atividade de produzir texto.

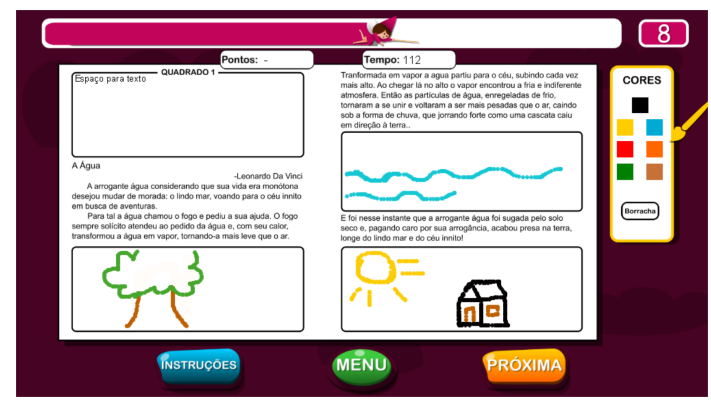

Figura 4. Atividade artística

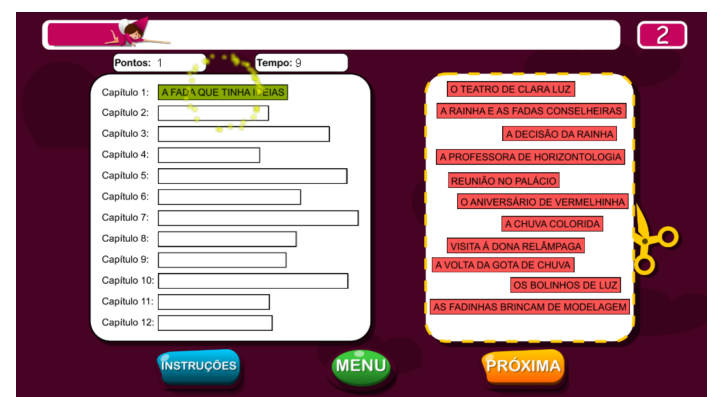

Figura 3. Atividade de arrastar e soltar

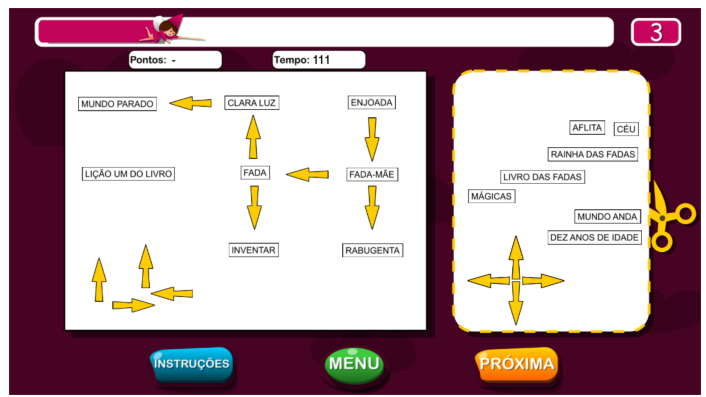

Figura 5. Atividade de mapa conceitual

\subsection{Avaliação}

A avaliação do portfólio digital foi realizada por meio da aplicação de questionários via Google Forms com um grupo de 5 professores da rede pública de ensino, após testarem-no. Essa aplicação divide-se em duas etapas:

- Na primeira etapa, foi realizado um teste de Interação Humano Computador (IHC) denominado de Teste de usabilidade de Nielsen (1993, 1994), que consiste na utilização de algumas heurísticas para verificar a interação que o usuário tem com o portfólio. Trata-se de um teste de caráter objetivo, onde o usuário lê algumas afirmações (heurísticas) e avalia se a afirmação em questão, remete-se bem ao portfólio digital, escolhendo 1 dentre 5 alternativas: 1-Discordo Fortemente, 2-Discordo, 3-Indiferente, 4-Concordo, 5-Concordo Fortemente. 
- Na segunda etapa, foi realizada uma avaliação mais subjetiva. Perguntou-se a opinião do professor sobre o quão bem as atividades do portfólio digital refletiam as atividades do portfólio físico. Em seguida, foi concedido um espaço para que o professor fizesse suas considerações sobre o portfólio digital como um todo.

No total, são 10 heurísticas citadas na primeira etapa, as quais os professores utilizaram para avaliar o portfólio. De forma resumida, são: 1-Utilização de linguagem simples, 2-Informações constantes sobre o progresso, 3-Total liberdade na realização das ações, 4-Induzir os usuários a cometerem erros que poderiam ter sido evitados, 5-Elementos iguais têm funções iguais em situações diferentes, 6-Os elementos são reconhecíveis pelos usuários sem a necessidade de memorizar, 7-Comandos podem ser facilitados por teclas de atalho, 8-Todas as informações na tela são importantes para a realização da atividade, 9-Os usuários têm acesso a ajuda quando necessário, 10-Quando acontecem erros, as mensagens são objetivas

\section{Resultados}

Nesta seção, apresentam-se os resultados da avaliação do Portfólio Digital "A fada que tinha ideias". A Tabela 1 mostra os resultados do teste de usabilidade de Nielsen (1993, 1994). O texto de cada heurística está simplificado para facilitar a visualização e o entendimento.

Tabela 1. Resultados do Teste de usabilidade de Nielsen

\begin{tabular}{|l|c|c|c|c|c|}
\hline & $\begin{array}{c}(1) \\
\text { Discordo } \\
\text { Fortemente }\end{array}$ & $\begin{array}{c}(2) \\
\text { Discordo }\end{array}$ & $\begin{array}{c}(3) \\
\text { Indiferent } \\
\text { e }\end{array}$ & $\begin{array}{c}(4) \\
\text { Concordo }\end{array}$ & $\begin{array}{c}(5) \\
\text { Concordo } \\
\text { fortemente }\end{array}$ \\
\hline $\begin{array}{l}\text { 1-Utilização de linguagem } \\
\text { simples. }\end{array}$ & $0 \%$ & $0 \%$ & $0 \%$ & $60 \%$ & $40 \%$ \\
\hline $\begin{array}{l}\text { 2-Informações constantes } \\
\text { sobre o progresso. }\end{array}$ & $20 \%$ & $0 \%$ & $0 \%$ & $60 \%$ & $20 \%$ \\
\hline $\begin{array}{l}\text { 3-Total liberdade na } \\
\text { realização das ações. }\end{array}$ & $0 \%$ & $60 \%$ & $0 \%$ & $0 \%$ & $40 \%$ \\
\hline $\begin{array}{l}\text { 4-Induzir os usuários a } \\
\text { cometerem erros. }\end{array}$ & $40 \%$ & $40 \%$ & $0 \%$ & $20 \%$ & $0 \%$ \\
\hline $\begin{array}{l}\text { 5-Elementos iguais tem } \\
\text { sempre, funções iguais. }\end{array}$ & $0 \%$ & $40 \%$ & $0 \%$ & $40 \%$ & $20 \%$ \\
\hline $\begin{array}{l}\text { 6-Elementos são } \\
\text { reconhecíveis sem a } \\
\text { necessidade de memorizar. }\end{array}$ & $0 \%$ & $20 \%$ & $0 \%$ & $40 \%$ & $40 \%$ \\
\hline 7-Comandos facilitados & $20 \%$ & $0 \%$ & $40 \%$ & $40 \%$ & $0 \%$ \\
\hline
\end{tabular}




\begin{tabular}{|l|c|c|c|c|c|}
\hline por teclas de atalho. & & & & & \\
\hline $\begin{array}{l}\text { 8-Todas as informações na } \\
\text { tela são importantes. }\end{array}$ & $0 \%$ & $0 \%$ & $0 \%$ & $60 \%$ & $40 \%$ \\
\hline $\begin{array}{l}\text { 9-Os usuários têm acesso } \\
\text { a ajuda quando necessário }\end{array}$ & $20 \%$ & $40 \%$ & $0 \%$ & $20 \%$ & $20 \%$ \\
\hline $\begin{array}{l}\text { 10-Quando acontecem } \\
\text { erros as mensagens são } \\
\text { objetivas. }\end{array}$ & $20 \%$ & $20 \%$ & $0 \%$ & $60 \%$ & $0 \%$ \\
\hline
\end{tabular}

Ao verificarem-se os resultados da avaliação, pode-se notar que, em sete das dez heurísticas utilizadas, pelo menos $60 \%$ dos avaliadores responderam de forma positiva quanto à sua existência no portfólio digital. Na heurística correspondente à facilitação de ações por meio de teclas de atalho (heurística 7), o resultado mostrou um valor intermediário. Nas outras duas heurísticas (heurísticas 3 e 9), houve um resultado negativo por parte dos avaliadores, sendo estas o foco principal para melhorias futuras no portfólio digital.

$\mathrm{Na}$ avaliação subjetiva, em que os professores foram convidados a avaliar o portfólio digital de maneira geral e dar suas considerações pessoais, obtiveram-se, em sua maioria, respostas positivas: "ficou legal!", "muito bem feito!", "gostei muito!". Houve também várias sugestões de melhorias: "mais espaço para digitar os textos", "mais instruções em determinados lugares", "melhorar o sistema de ajuda".

\section{Conclusão e considerações finais}

Este trabalho teve como objetivo apresentar o processo de concepção e desenvolvimento da virtualização do portfólio de atividades didáticas "A fada que tinha ideias". Esta versão digital foi criada com o intuito de possibilitar a utilização deste portfólio de maneira remota e online, reduzindo seu custo de aplicação.

Com base nas avaliações, algumas pequenas melhorias fazem-se necessárias, mas o portfólio digital foi aprovado pelos avaliadores. Como trabalho futuro, deve-se testar a eficácia acadêmica de sua utilização, aplicando-o aos alunos no nível de alfabetização para verificar seu fator de impacto nas habilidades de leitura.

\section{Referências}

ALMEIDA, Fernanda Lopes; EDÚ. A fada que tinha idéias. Ática, 1976.

BROUSSEAU, Guy. Os diferentes papéis do professor. Parra: C. \& Saiz, I.(Orgs.), 1996.

BULHÕES, Daniel Brito; ASSIS, Luciana Pereira; BODOLAY, Adriana Nascimento; ANDRADE, Alessandro Vivas; PITANGUI, Cristiano Grijó. Professora Vitória: um 
Chatbot para o ensino da Leitura. In: SIMPÓSIO BRASILEIRO DE INFORMÁTICA NA EDUCAÇÃO, 31. , 2020, Online. Anais [...]. Porto Alegre: Sociedade Brasileira de Computação, 2020. p. 451-460. DOI: https://doi.org/10.5753/cbie.sbie.2020.451.

CECCON, Diogo Luiz; PORTO, Josiane Brietzke. BcS: Jogos Digitais no Auxílio do Desenvolvimento de Crianças Especiais com Atraso na Linguagem. In: SIMPÓSIO BRASILEIRO DE INFORMÁTICA NA EDUCAÇÃO, 31. , 2020, Online. Anais [...]. Porto Alegre: Sociedade Brasileira de Computação, 2020. p. 522-531. DOI: https://doi.org/10.5753/cbie.sbie.2020.522.

CHAROLLES, Michel. Introduction aux problèmes de la cohérence des textes. Langue Française. Paris: Larousse, n.38, p.7-41, mai 1978.

CHEVALLARD, Yves. Sobre a teoria da transposição didática: algumas considerações introdutórias. Revista de educação, ciências e matemática, v. 3, n. 2, 2013.

CORDEIRO, Karolina. O Impacto da Pandemia na Educação: A Utilização da Tecnologia como Ferramenta de Ensino. Brasil: Faculdades IDAAM. 2020.

DEHAENE, Stanislas. Les neurones de la lecture. Paris: Odile Jacob, 2012.

FREIRE, Paulo. Pedagogia do oprimido. Ed. Rio de Janeiro: Paz \& Terra, 1988.

GOMBERT, J. . Metalinguistic Development. Chicago: University of Chicago, 1992.

GOODMAN, Kenneth S. Unidade na leitura - um modelo psicolingüístico transacional. Letras de Hoje, n. 86, p. 9-43. Porto Alegre: EDIPUCRS: 1991.

HALLIDAY, M. A. K. \& HASAN, R. Cohesion in English. London: Longman,1976.

KATO, M. A. O aprendizado da leitura. São Paulo: Martins Fontes,2007.

LEMOS, Regiane F. F.. O uso dos jogos digitais como atividades didáticas no $2^{\circ}$ ano do ensino fundamental. TCC(especialização) - Universidade Federal de Santa Catarina. Centro de Ciências da Educação. Departamento de Metodologia de Ensino. Educação na Cultura Digital. set 2016.

MELO, Marcus Vinicius Cardoso de; SEGATO, Tiago; MOMBACH, Jaline. Apolo: Versão Digital de um Jogo de Tabuleiro para Apoio ao Ensino na Educação Básica. Brazilian Symposium on Computers in Education (Simpósio Brasileiro de Informática na Educação - SBIE), [S.1.], p. 873, nov. 2019. ISSN 2316-6533. Disponível em: <https://br-ie.org/pub/index.php/sbie/article/view/8815>. Acesso em: 26 jul. 2021. doi:http://dx.doi.org/10.5753/cbie.sbie.2019.873.

NASCHOLD, Angela. Chuvas. et al (Coord.) Projeto Leitura + Neurociências: interfaces na educação integral. Natal: Universidade Federal do Rio Grande do Norte, $2018 . \quad$ Disponível em: https://palavras.appform.pt/ojs/index.php/revista/article/view/46. Acesso: 14 set. 2021. 
NASCHOLD, Angela. Chuvas. Portfólio Didático da História "A fada que tinha ideias" Natal: Universidade Federal do Rio Grande do Norte, 2019.

NICOLESCU, Basarab et al. O manifesto da transdisciplinaridade. 1999.

NIELSEN, Jakob. Response times: the three important limits. Usability Engineering. 1993.

NIELSEN, Jakob. Usability engineering: Elsevier. 1994.

NOVAK, Joseph D.; CAÑAS, Alberto J. A teoria subjacente aos mapas conceituais e como elaborá-los e usá-los. Práxis Educativa, v. 5, n. 1, p. 9-29, 2010.

OLIVEIRA, Vinicius Gangana de; Porrozzi, Renato. Possibilidades e limitações da informática na educação. Revista Praxis v. 1, n. 1. 2009.

OLIVEIRA, Paulo; FONTOURA, Lisandra; MEDINA, Roseclea Duarte. Metodologias Usadas no Desenvolvimento de Jogos Eletrônicos Educacionais: Uma Revisão da Literatura. In: SIMPÓSIO BRASILEIRO DE INFORMÁTICA NA EDUCAÇÃO, 31. , 2020, Online. Anais [...]. Porto Alegre: Sociedade Brasileira de Computação, 2020. p. 542-551. DOI: https://doi.org/10.5753/cbie.sbie.2020.542.

PEREIRA, V.W. (org.). Aprendizado da leitura: ciências e literatura no fio da história. Porto Alegre: EDIPUCRS, 2009.

SANTOS, Leila M. A.; Tarouco, Liane M. R. A importância do estudo da teoria da carga cognitiva em uma educação tecnológica. Revista Novas Tecnologias na Educação v. 5, n. 1. 2007.

SMIDERLE, Rodrigo; RIGO, Sandro; JAQUES, Patricia. Estudando o impacto da gamificação na aprendizagem e engajamento de alunos de acordo com os traços de personalidade e a orientação motivacional. Brazilian Symposium on Computers in Education (Simpósio Brasileiro de Informática na Educação - SBIE), [S.1.], p. 793, nov. 2019. ISSN 2316-6533. Disponível em: $<$ https://br-ie.org/pub/index.php/sbie/article/view/8807>. Acesso em: 26 jul. 2021. doi:http://dx.doi.org/10.5753/cbie.sbie.2019.793.

SOLÉ, Isabel. Estratégias de Leitura. Porto Alegre: Penso Editora, 2015. 